\title{
Sociodemographic and Scanographic Aspects of Primary Bronchopulmonary Cancer in a Hospital in Mali
}

\author{
Mody Abdoulaye Camara1*, Moussa Abdoulaye Ouattara², Hawa Diarra1, \\ Mohamed Maba Traore1, Boubacar Mama Toure'1, Nouhoum Simpara1, Néné Koumare3, \\ Mamadou Ndiaye", Salia Coulibaly4, Abdoulaye Kones, Moussa Konate ${ }^{5}$, Ilias Guindo3, \\ Konate Zakaria1, Mamadou Bakary Coulibaly ${ }^{7,8}$, Seydou Coulibaly ${ }^{1}$, Siaka Sidibe ${ }^{5}$
}

\footnotetext{
${ }^{1}$ Department of Medical Imaging of the Mali Hospital, Bamako, Mali

${ }^{2}$ Department of Thoracic Surgery of the Mlai Hospital, Bamako, Mali

${ }^{3}$ Pediatric Unit at the Common Reference Health Center VI, Bamako, Mali

${ }^{4}$ Department of Medical Imaging of the CHU of Kati, Bamako, Mali

${ }^{5}$ Bamako Infirmary Hospital, Bamako, Mali

${ }^{6}$ Medical Imaging Department of the CHU Point G, Bamako, Mali

${ }^{7}$ Medical Imaging Department of CHME Luxembourg, Bamako, Mali

${ }^{8}$ Department of Gynecology of the Mali Hospital, Bamako, Mali

Email: ^drmacamara@yahoo.fr
}

\begin{abstract}
How to cite this paper: Camara, M.A. Ouattara, M.A., Diarra, H., Traore, M.M., Toure, B.M., Simpara, N., Koumare, N., Ndiaye, M., Coulibaly, S., Kone, A., Konate, M., Guindo, I., Zakaria, K., Coulibaly, M.B., Coulibaly, S. and Sidibe, S. (2021) Sociodemographic and Scanographic Aspects of Primary Bronchopulmonary Cancer in a Hospital in Mali. Open Journal of Medical Imaging, 11, 104-114.

https://doi.org/10.4236/ojmi.2021.114010
\end{abstract}

Received: September 8, 2021

Accepted: October 30, 2021

Published: November 2, 2021

Copyright $\odot 2021$ by author(s) and Scientific Research Publishing Inc. This work is licensed under the Creative Commons Attribution International License (CC BY 4.0)

http://creativecommons.org/licenses/by/4.0/

(c) $\underset{\mathrm{Br}}{\mathrm{Br}}$ Open Access

\begin{abstract}
Summary: A malignant tumour that develops from the bronchial epithelium and then invades the lungs. It ranks third after colorectal and breast cancer. In Mali, computed tomography (CT) is the main imaging tool used at all stages of treatment. We had initiated this study with the objective of specifying the place of CT in the diagnosis of primary bronchopulmonary cancer at the hospital of Mali. Method: This is a prospective and descriptive study conducted by the Medical Imaging and Thoracic Surgery departments at Mali Hospital from March 2014 to February 2015. All the patients who have benefited from a CT scan and presenting at least one histologically confirmed bronchopulmonary tumor were included. Results: We were recruiting $60 \mathrm{pa}-$ tients with bronchopulmonary cancers out of 500 referred for a thoracic CT scan performed, a frequency of $12 \%$. There was one male patient with a sex ratio of $4 \mathrm{H} / 1 \mathrm{~F}$. The average age was 60 years. The history of smoking was $85 \%$. The symptoms were dominated by general condition $(63.33 \%)$, cough (25\%) and haemoptysis (58.33\%). CT scans were performed in all patients. The lesions were located more in the lower lobes (71\%). The tumours were: heterogeneous tissue density (70\%), spiculated contours (80\%), and the histology was more non-small cell carcinoma. Conclusion: The incidence of
\end{abstract}


bronchopulmonary cancer is very high and its prognosis is poor at an advanced stage. The evaluative role of CT and biopsy guidance has given it a place of choice in its management. The diagnosis of certainty remains histology.

\section{Keywords}

Bronchopulmonary Cancer, CT, Mali Hospital

\section{Introduction}

Bronchopulmonary cancer is a malignant tumour that develops from the bronchial epithelium and subsequently invades the lungs [1]. Histologically, there are two main groups: non-small cell lung cancer (NSCLC), which accounts for more than $80 \%$ of cases, and small cell lung cancer (SCLC), which accounts for about $15 \%$ of cases. These two entities have different clinical, therapeutic and prognostic characteristics [2]. It is a real public health problem [3] [4]. Paradoxically, one of its particularities is that it is accessible to prevention since its main risk factor, smoking has been identified [3] [5]. In 2018, according to GLOBOCAN, the worldwide incidence was estimated at $2,093,876$ cases ( $11.6 \%$ of all cancers) for an estimated $1,761,007$ deaths (18.4\% of all cancer deaths), making it the most deadly cancer. In West Africa in general, the incidence during the same year was estimated at 3.6 new cases per 100,000 inhabitants [6]. In Mali, according to data from the cancer registry, bronchopulmonary cancers represent $2 \%$ of all cancers [7].

The role of CT is essential in the management of patients with bronchopulmonary cancer:

- diagnostic: initial or pre-therapeutic extension assessment;

- percutaneous biopsy guidance;

- per and post surveillance [6].

CT has become one of the main medical imaging techniques. It is of major interest in the diagnosis (evaluation and monitoring) and treatment of certain stages of the disease. According to the radiological series, we are witnessing an increasingly high frequency and a late diagnosis, thus making its prognosis appalling. This is a cause for concern and invites us to take stock. We undertook this study with the aim of specifying the place of computed tomography (CT) in the diagnosis of primary bronchopulmonary cancer in the medical imaging department of the Mali hospital.

\section{Materials and Methods}

This was a descriptive and prospective study from March 2014 to February 2015 (12 months). It took place in the medical imaging and thoracic surgery departments at Mali Hospital. It concerned all patients of any age who had received a CT scan at the Mali Hospital during the period.

All patients with histologically confirmed cancer who received a thoracic CT 
scan at Mali Hospital during the study period were included in the study. Patients with non-histologically confirmed bronchopulmonary cancer and patients who underwent CT scans outside the hospital in Mali were not included. The variables studied were: sociodemographic (age, sex, medical history and occupation), clinical (cough, haemoptysis and general condition), histological and scanographic (lesion characteristics, lymph node involvement and metastases).

The CT examinations were performed with a Siemens Emotion 16 Slices machine. The radiological films were printed with an AGFA DRY STAR printer.

At the reception, the patients were given a psychological preparation and the dosage of creatinemia in order to eliminate a contraindication to the injection of the iodine contrast agent $350 \mathrm{mg}$. On the day of the examination, the patient fasted for 06 hours before the examination; a catheter (18 or 20 left) was placed in the elbow. The patient was positioned supine with his arms raised above his head. The $05 \mathrm{~mm}$ helical acquisition is from the distal $1 / 2$ of the neck to the adrenals. A multiplanar reconstruction in triple fenestration (mediastinal, pulmonary and bone) was principle. It was performed without and then with intravenous injection of iodine at a dose of $1 \mathrm{ml} / \mathrm{kg}$ of $350 \mathrm{mg}$ iodine with a flow rate of $3-4 \mathrm{ml} /$ second.

The trans-thoracic scan-guided biopsy was performed by appointment. After psychological and physical preparation of the patient, and comfortable installation on the table, local anaesthesia with $6-8 \mathrm{ml}$ of lidocaine $2 \%$ at the puncture site was performed after rigorous local asepsis with BetadineR.

The puncture was performed after locating the site with the laser scanner and using a needle in place. We took at least three (03) samples (cores) immersed in formalin and taken with 14 - $18 \mathrm{G}$ trocars (needles).

The duration of the biopsy varied from 25 to 40 minutes. A control chest film was taken 20 - 30 minutes after the biopsy to ensure that there was no pneumothorax.

Our data were collected on an individual survey form, radiological reports, and patient records.

The images were collected in the database of the imaging department. We took care to respect the anonymity of the patients on the images.

Data entry was done using Word 2010 and data analysis was done using SPSS 22.0 .

\section{Results}

The study population was 500 patients, among whom we recruited 60 patients with histologically confirmed bronchopulmonary cancers, i.e. a frequency of $12 \%$. The average age was 60 years with extremes of $41-89$ years and with a male predominance (sex ratio of $4 \mathrm{H} / 1 \mathrm{~F}$ ). The medical history (ATCD) was mainly smoking (85\% of them, $91 \%$ were active) and tuberculosis (5\%). The average duration of exposure to tobacco was 25 years, with an average consumption of 26 packs/year. The main clinical signs found were: alteration of the gen- 
eral state of health (63.33\%), haemoptysis (58.33\%) and cough (25\%). Chest $\mathrm{X}$-rays showed opacity suspicious of cancer in $30.2 \%$ of cases and were normal in $19.2 \%$ of cases (Table 1 ). We performed a CT scan in all patients. The cancerous lesions found were of different tissue densities: single (85\%), heterogeneous $(86.7 \%)$, spiculated (80\%) (Figure 1), and located more in the lower lobes of the lungs. The average size was $05 \mathrm{~cm}$ long axis, with heterogeneous enhancement after IV iodine (86.7\%). We found suspicious adenopathies in $80 \%$ of

Table 1. Distribution of patients by socio-demographic and clinical data.

\begin{tabular}{|c|c|c|c|}
\hline & Characteristic. & Effective $(n=60)$ & Percentage $\%$ \\
\hline \multirow{3}{*}{ Age (year) } & Age average & 60 & \\
\hline & $51-60$ & 23 & 38.33 \\
\hline & $61-70$ & 20 & 33.33 \\
\hline \multirow{2}{*}{ Gender } & Male & 48 & 80 \\
\hline & Female & 12 & 20 \\
\hline \multirow{3}{*}{ Risk factors } & Treated tuberculosis & 3 & 5 \\
\hline & Tabacco & 51 & 85 \\
\hline & No ACTD & 6 & 10 \\
\hline \multirow{2}{*}{ Occupation } & Civil serviant & 24 & 40 \\
\hline & Housewife & 10 & 16.7 \\
\hline \multirow{3}{*}{ Clinic } & Deterioration of general condition & 38 & 63.33 \\
\hline & Cough & 15 & 25 \\
\hline & Hemoptysis & 35 & 58.33 \\
\hline \multirow{2}{*}{$\begin{array}{l}\text { Histology; bronchial } \\
\text { carcinoma }\end{array}$} & No to small cell & 50 & 83.3 \\
\hline & Small cell & 10 & 16.7 \\
\hline \multirow{3}{*}{$\begin{array}{c}\text { Type of } \\
\text { biopsy sample }\end{array}$} & Bronchoscopy & 40 & 66.6 \\
\hline & Pleural puncture & 10 & 16.7 \\
\hline & Percutaneous biopsy & 10 & 16.7 \\
\hline
\end{tabular}

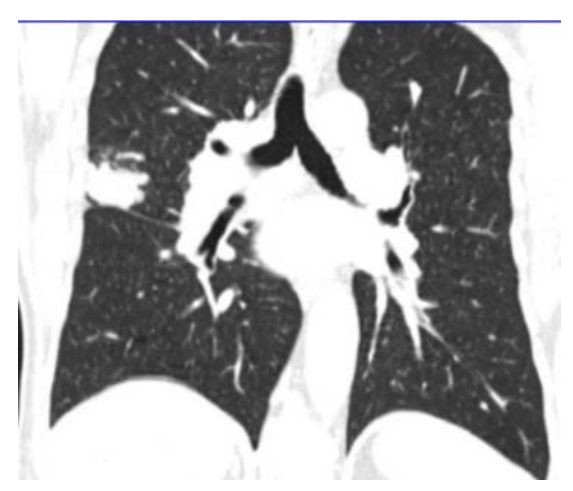

Figure 1. thoracic CT scan: coronal reconstruction showing a dense, homogeneous opacity with spiculated contours suggestive of right lung cancer confirmed by pathological study. 
patients (Figure 2 and Figure 3). The secondary lesions found were: pleural (28\%) (Figure 4) hepatic (28\%) (Figure 5), brain (3.33\%), bone (3.33\%), and splenic (1.6\%). The mode of biopsy sampling for pathological examination was: trans-thoracic (33.4\%) and endoscopic (66.6\%). The histological type was non-small cell (83.3\%) and small cell (16.7\%) carcinoma (Table 2).

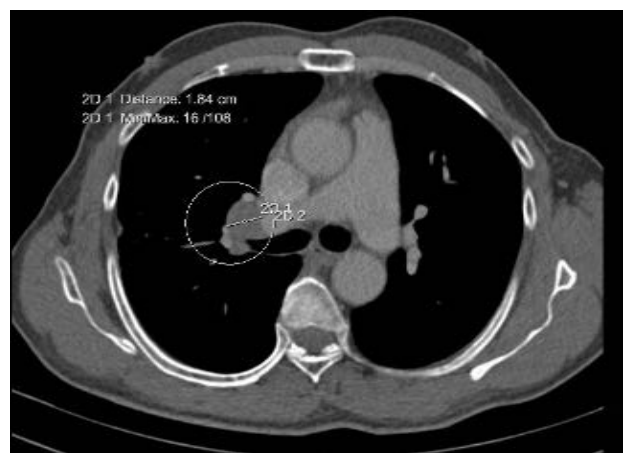

Figure 2. Thoracic CT scan: axial section in mediastinal window showing a well-limited hypodense lesion with irregular contours suggestive of right bronchopulmonary cancer confirmed on pathological study.

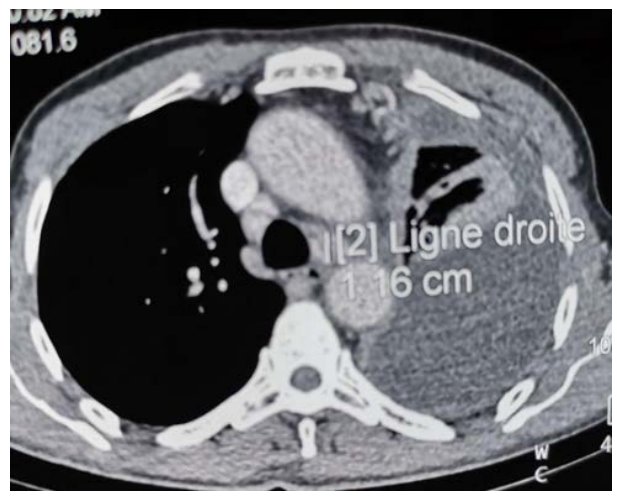

Figure 3. Thoracic CT scan axial, injected showing supra-centimetric mediastinal adenopathy homolateral to the tumour.

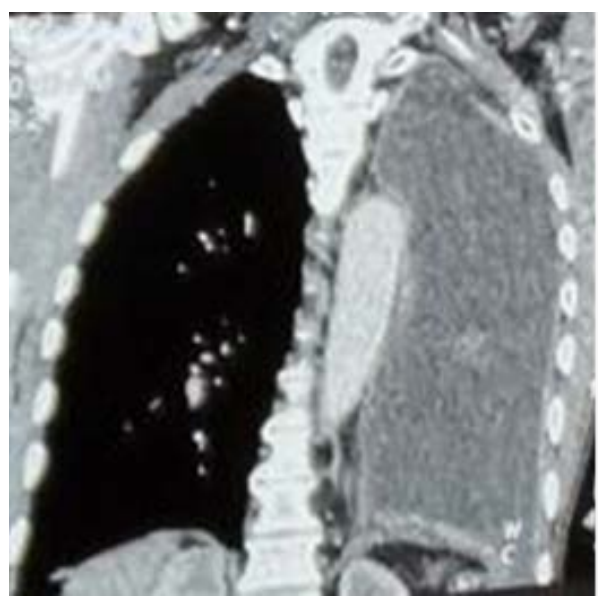

Figure 4. Thoracic CT scan injected: coronal reconstruction chest CT in mediastinal window showing a large left pleurisy. 


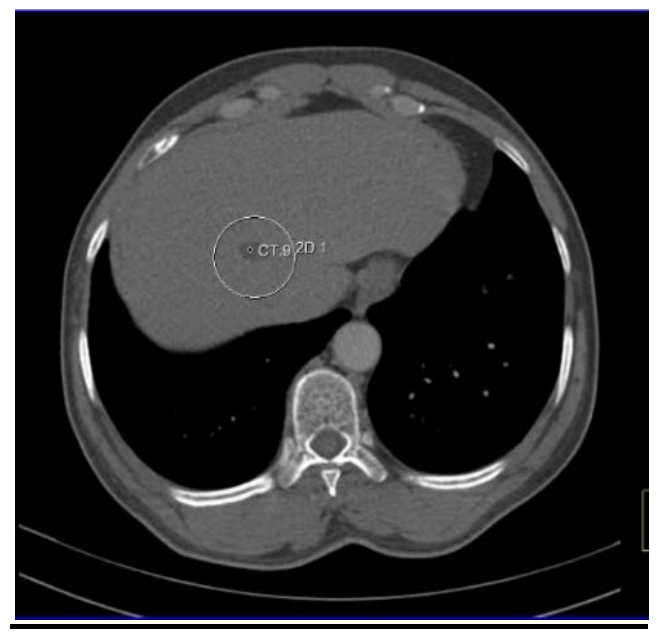

Figure 5. Chest CT axial section in mediastinal window showing a small hypodense lesion in the right liver.

Table 2. Distribution of patients according to scan data.

\begin{tabular}{|c|c|c|c|}
\hline \multicolumn{2}{|c|}{ CT characteristic } & Effective $n=60$ & Percentage $\%$ \\
\hline \multirow{2}{*}{ Tissue density } & Homogeneous & 10 & 16.67 \\
\hline & Hétérogeneous & 50 & 83.33 \\
\hline \multirow{2}{*}{ Number } & Single & 51 & 85 \\
\hline & Multiple & 9 & 15 \\
\hline \multirow{3}{*}{ Size } & Less than $3 \mathrm{~cm}$ & 12 & 20 \\
\hline & $3-5 \mathrm{~cm}$ & 28 & 46.67 \\
\hline & Greater than $5 \mathrm{~cm}$ & 20 & 33.33 \\
\hline \multirow{2}{*}{ Outlines } & Regular & 9 & 15 \\
\hline & Spiculated & 51 & 85 \\
\hline \multirow{3}{*}{ Location } & Upper lobe & 16 & 26.67 \\
\hline & Middle lobe & 4 & 6.66 \\
\hline & Lower lobe & 49 & 81.67 \\
\hline \multirow{3}{*}{ Lymph node involvement } & No & 12 & 20 \\
\hline & $\mathrm{N} 1+\mathrm{N} 2$ & 28 & 46.67 \\
\hline & N3 & 20 & 33.33 \\
\hline \multirow{5}{*}{ Distance involvement } & Pleurisy & 17 & 28.33 \\
\hline & Liver & 17 & 28.33 \\
\hline & Brain & 2 & 3.33 \\
\hline & BONE & 2 & 3.33 \\
\hline & Splenic & 1 & 1.6 \\
\hline \multirow{3}{*}{ Type of biopsy sample } & Bronchoscopy & 40 & 66.66 \\
\hline & Pleural puncture & 10 & 16.67 \\
\hline & Percutaneous biopsy & 10 & 66.67 \\
\hline
\end{tabular}




\section{Discussion}

\subsection{Sociodemographic Characteristics}

We collected 60 patients with confirmed bronchopulmonary cancers out of 500 thoracic CT scans, i.e. a hospital frequency of $12 \%$ with a clear male predominance (sex ratio: $4 \mathrm{H} / 1 \mathrm{~F}$ ). The average age of our patients was 60 years. This result is close to those of Tiadjue in Mali in 2019 (14.08), Ouédraogo [8], in Burkina (14.65\%) but clearly higher than that of Ben Ahmed [9] in Algeria (1.80\%).

Male sex predominated in our study (80\%), this was similar to that of Tiadjue [10], El Ouazzani et al. [11]. However, it was different from that of Ridene et al. [12] found a female predominance (77\%). This could be explained by the fact that exposure to risk factors was not necessarily related to gender.

Civil servants accounted for $40 \%$ in our study, in contrast to the studies of Tiadjue [10], who found equal proportions of retired people and housewives.

\subsection{History}

In our study, smoking accounted for $85 \%$. Active smoking was noted in 48 cases and passive smoking in 03 cases. The risk factor for smoking is the same as in other studies: Tadjué [10], Abderrahim et al. [13], Jabri [14] in Morocco and Ketf [15] in Algiers. This would explain that smoking is a risk factor for bronchopulmonary cancer. Other risk factors are also suspected such as occupational exposures (painters, welders and heavy machinery mechanics) were reported in the Ketf's study [15] in Algiers. Pulmonary tuberculosis was confirmed and treated in $5.6 \%$ in our study.

This rate was lower than that of Souki et al. [16] who found 30\% of cases of confirmed and treated pulmonary tuberculosis [15].

\subsection{Clinical Signs}

The main clinical signs found were: alteration of general condition (AEG) (63.33\%), haemoptysis (53.33\%) and cough (25\%). This result was superior to that of H. El Ouazzani et al. [11] who found haemoptysis associated with AEG in $25 \%$ of patients. These could be explained by the late diagnosis.

\subsection{Radiographic Aspects}

Chest radiography was found in $40.1 \%$ of our patients. It showed suspicious opacities in $30.2 \%$ of cases and was normal in $9.2 \%$ of cases.

This result is comparable to that of El Ouazzani et al. [11] who found opacities in $38 \%$ of cases. A normal chest X-ray does not formally exclude a bronchopulmonary tumour.

\subsection{CT Aspects}

The role of the CT scan is to evaluate the lesion, the respectability of the tumour, the extension and to guide the trans-parietal biopsies by coring. However, PET scans are superior to conventional scans in detecting lymph node lesions and 
extra-brain lesions. The staging stage consists of assessing the tumour status, $\mathrm{T}$, and determining whether the lesion can be completely removed by surgery. It is used to guide bronchoscopy, to determine the $\mathrm{T}$ descriptor, to some extent the $\mathrm{N}$ (lymph node) and M (metastasis) status, according to Beigelman-Aubrya, et al. [17].

According to the TNM Thoracic Oncology Guidelines 8th edition, Tumour size is classified as $\mathrm{T} 1 \leq 3 \mathrm{~cm}, 3 \mathrm{~cm}<\mathrm{T} 2 \leq 5 \mathrm{~cm}, 5 \mathrm{~cm}<\mathrm{T} 3 \leq 7 \mathrm{~cm}$, and $\mathrm{T} 4>7 \mathrm{~cm}$.

Lymph node involvement:

N0: absence N1: homolateral peri-bronchial or peri-hilar nodes N2: homolateral or subcarinal mediastinal nodes and N3; contralateral lateral, supraclavicular, mediastinal or nodes scalene nodes.

Distant involvement:

M0: no metastasis M1: metastasis

The lung lesion was unique (85\%) in all cases. We found tissue density opacities (hypo or iso dense) with irregular or spiculated contours. Tissue lesions with spiculated contours are highly suspicious of cancer until histologically proven otherwise. These are identical in other studies Souki [16], Beigelman-Aubrya et al. [17], Ayadil et al. [18].

The contours were spiculated in $80 \%$ of cases, which is comparable to the result of Souki et al. [16] in whom the contours were spiculated in $60 \%$ of cases. This sign is suggestive of malignancy.

The lesions are classified into: $\mathrm{T} 1 \leq 3 \mathrm{~cm}, 3 \mathrm{~cm}<\mathrm{T} 2 \leq 5 \mathrm{~cm}, 5 \mathrm{~cm}<\mathrm{T} 3 \leq 7 \mathrm{~cm}$ and $\mathrm{T} 4>7$ those located the size of our tumours was variable with an average of 5 $\mathrm{cm}$ long axis. The sizes of these lesions were: less than $3 \mathrm{~cm} \mathrm{(20 \% ),} \mathrm{those} \mathrm{be-}$ tween $3-5 \mathrm{~cm}(46.67 \%)$ and those between $5 \mathrm{~cm}$ and $07 \mathrm{~cm}$ (33.33\%). This result is opposed to that of Souki et al. [16] who found a mean size of $2 \mathrm{~cm}$ long axis.

The tumours were associated with lymph node involvement $(\mathrm{N})$ : mediastinal in $80 \%$ of cases. Our stages were N0 (20\%) N1 + N2 (46.67\%) and N3 (33.33\%). Our figures were higher than those of $\mathrm{H}$. El Ouazzani et al. [11] who found mediastinal adenopathy in $37 \%$ of cases. The high percentage of mediastinal adenopathy in our series could be explained by the fact that our patients were seen in advanced stages. These opacities were also associated with pleurisy in $28 \%$ of cases.

The lung lesion was unique in $85 \%$ of cases.

The lesions predominated in the lower lobes in our series in $71 \%$ of cases. This was in contrast to Clemence [19] in whom lesions predominated in the upper lobes in $73 \%$ of cases.

Distant metastases were $28.3 \%$ in our series. This rate is lower than that of A. Prévost et al. [20] who found $37 \%$ of cases. This indicates a late diagnosis of the disease.

\subsection{Histological Type}

Bronchoscopy and sampling procedures will be more effective if guided by CT. 
The diagnosis of cancer requires histology, and core biopsy material is preferable to fine needle cytology [7]. Our study found non-small cell lung carcinoma in 50 patients $(83.3 \%)$. Carcinoma is the most frequent histological type, especially in smokers. This is supported by the literature: H. El Ouazzani [11], Ketfi [15] in Ben-Alla [21] in Morocco in 2015, Algiers, and in Moussoki [22] in France in 2014.

Thes limits of our study:

- We had one case of allergy to the contrast medium, one case of extravasation of the contrast medium by venous perforation.

- CT scan failure over a period of 04 weeks.

- CT biopsy could only be performed in 40 cases.

- Lack of histology results in some patients.

- The high cost of trans-thoracic biopsies.

- A case of pneumothorax in an emphysematous patient was referred to the emergency department.

\section{Conclusion}

The frequency of bronchopulmonary cancer diagnosed at an advanced stage (at least stage II) is very high. The evaluative role of the CT scan and biopsy guidance has given it a place of choice in its management. The diagnosis of certainty remains histology.

\section{Author Approval}

All authors agree to the submission of this article.

\section{Consent}

For this work, we received the consent of the patient; that of the department head and the director of the Hôpital du Mali.

\section{Conflicts of Interest}

The authors have declared no conflicts of interest.

\section{References}

[1] FerlayShin, H.R., Bray, F., Forman, D., Mathers, C. and Parkin, D.M. (2010) Estimates of Worldwide Burden of Cancer in 2008: GLOBOCAN 2008. International Journal of Cancer, 127, 917

[2] El-Bouhali, A. (2016) Profile of Bronchopulmonary Cancers Hospitalised at the Avicenne Military Hospital. These of Medicine and Pharmacy of Marrakech a Maraco.

[3] Bouvenot, G., Devolder, B. and Quillevin, L. (1994) Pathologie médicale. Masson, Issy-les-Moulineaux, 411-413.

[4] Type, J.B., Warner, K.E. and Glantz, S.A. (1987) Tobacco Advertising and Consumption: Evidence of a Causal Relationship. World Smoking and Health, 8, 492-508.

[5] El-Bouhali, A. (2016) Profile of Bronchopulmonary Cancers Hospitalised at the 
Avicenne Military Hospital from January 2010 to January 2015. Thesis of Medicine, Cadi Ayyad University, Marrakesh.

[6] Bray, F., et al. (2018) Global Cancer Statistics 2018: GLOBOCAN Estimates of Incidence and Mortality Worldwide for 36 Cancers in 185 Countries. CA: A Cancer Journal for Clinicians, 68, 394-424.

[7] Diarra, A. (2009) Epidemiological and Histo-Pathological Aspects of Bronchopulmonary Cancers in Bamako: Data from the Cancer Register. Thesis of Medicine, USTTB.

[8] Ouedraogo, V.G. (2003) Bronchopulmonary Cancers at the Yalgado Ouedraogo National Hospital: Epidemiological, Clinical and Diagnostic Aspects. Thesis of Medicine, University of Ouagadougou, Ouagadougou.

[9] Ben Ahmed, A. and Kouroughli, M. (1998) La place du cancer du poumon dans un service de médecine à Alger. Communication to the Algerian Society of Pneumo-Phtisiology.

[10] Tiadjue, M. (2019) Epidemiological and Anatomopathological Aspects of Bronchopulmonary Cancers in the Service of Anatomy and Cytology Pathology of the CHU of Point G. Thesis of Medicine Bamako Mali, 78-83.

[11] El Ouazzani, H., Menchafou, I., Achachi, L., EL Ftouh, M. and El FassyFihry, M.T. (2010) Delayed Diagnosis of Primary Bronchial Cancer. Study Carried Out in the Pneumology Department of the Ibn Sina University Hospital in Rabat (Morocco). Revue de Pneumologie Clinique, 66, 335.

[12] Ridene, I., Radhouani, I., Ayadi, A., Zidi, A., Hantous-Zannad, S. and Baccouche, I. (2010) Imaging of Primary Pulmonary Lymphomas. Revue des Maladies Respiratoires, 24, 1069-1076.

[13] Abderrahim, S., Belkaceum, S., Kheloui, Y., Lehadi, A., Nacef, L. and Saighi, O. (2012) Thoracic Cancers of the Young Subject: About 50 Cases in Blida, Algeria. 16th Congress of Pneumology of the French Language, Lyon, 27-29 January 2012, 140.

[14] Jabri, L., et al. (1999) Diagnostic Yield of Fibroscopic Specimens in Bronchopulmonary Cancers. Maghreb Médical, Tunis.

[15] Ketfi, A., Zanoun, N., Laouedj, I., Gharnaout, M. and Fraga, S. (2020) Primary Bronchial Cancer and Occupational Risks in a North African Population. The Pan African Medical Journal, 37, 120.

[16] Souki, N., Jabri, H., Moubachir, H., El Khattabi, W. and Afif, H. (2016) Etiological Profile of Single Pulmonary Nodule. Journal of Respiratory Diseases, 33, 100.

[17] Beigelman-Aubrya, C., Duneta, V. and Brunb, A.-L. (2016) CT Imaging in Pre-Therapeutic Assessment Diagnostic and Interventional Imaging. Diagnostic and Interventional Imaging, 97, 973-989.

[18] Ayadi, W., Siala, I., Chaker, M., et al. (2005) Imaging of Bronchopulmonary Cancers. Journal of Radiology, 86, 1579.

[19] Valla, C. (2014) Prognostic Value of PET-CT in Non-Metastatic Non-Small Cell Lung Cancers. Thesis Med-Poitiers, 65.

[20] Prévost, A., Papthanassiou, D., Jovenin, N., Menéroux, B., Cuif-Job, A. and Bruna-Muraille, C. (2009) Comparison between PET and CT in the Extension Workup of Bronchopulmonary Cancer, Consequences for Operability in 94 Patients. Revue de Pneumologie Clinique, 65, 341.

[21] Ben Alla, S.A.A. (2016) Primary Bronchial Cancer: About 228 Cases, Experience of the Pneumology Department of Moulay Ismail Military Hospital in Meknes, Thesis 
of Medicine, Sidi Mohammed Ben Abdellah University, Morocco, 135.

[22] Moussoki, P.G. (2014) Descriptive and Comparative Study of the 63 Patients of the Year 2010 and the 45 Patients of the Year 2000 with Primary Bronchial Cancer at the Hospital Centre of Périgueux. Thesis of Medicine, University of Bordeaux, Bordeaux. 